\title{
Characteristics of Young-Onset and Late-Onset Dementia Patients at a Remote Memory Clinic
}

\author{
Jennifer F. W. Wong, Andrew Kirk, Landon Perlett, Chandima Karunanayake, \\ Debra Morgan, Megan E. O’Connell
}

\begin{abstract}
Background: Young-onset dementia (YOD) is defined as the onset of dementia symptoms before the age of 65 years and accounts for $2-8 \%$ of dementia. YOD patients and their caregivers face unique challenges in diagnosis and management. We aimed to compare the characteristics of rural YOD and late-onset dementia (LOD) patients at a rural and remote memory clinic in Western Canada. Methods: A total of 333 consecutive patients (YOD $=61, \mathrm{LOD}=272$ ) at a rural and remote memory clinic between March 2004 and July 2016 were included in this study. Each patient had neuropsychological assessment. Health, mood, function, behaviour and social factors were also measured. Both groups were compared using $\chi^{2}$ tests and independent sample tests. Results: YOD patients were more likely to be married, employed, current smokers and highly educated. They reported fewer cognitive symptoms, but had more depressive symptoms. YOD patients were less likely to live alone and use homecare services. YOD caregivers were also more likely to be a spouse and had higher levels of distress than LOD caregivers. Both YOD and LOD patient groups were equally likely to have a driver's licence. Conclusions: Our findings indicate YOD and LOD patients have distinct characteristics and services must be modified to better meet YOD patient needs. In particular, the use of homecare services and caregiver support may alleviate the higher levels of distress found in YOD patients and their caregivers. Additional research should be directed to addressing YOD patient depression, caregiver distress and barriers to services.
\end{abstract}

RÉSUMÉ : Les caractéristiques de patients atteints de démence précoce et tardive traités dans une clinique de la mémoire située en région éloignée. Contexte : La démence à début précoce (DDP) peut être définie par l'apparition de premiers symptômes chez des patients âgés de moins de 65 ans. Elle représente de 2 à $8 \%$ des cas de démence. À ce sujet, les patients atteints de DDP et leurs aidants naturels font face à des défis particuliers en matière de diagnostic et de prise en charge de cette maladie. Nous entendons ici comparer les caractéristiques de patients atteints de DPP à celles de cas de démence tardive (DT). À noter que tous ces patients étaient traités dans une clinique de la mémoire de l'Ouest canadien située en région éloignée. Méthodes : Au total, 333 patients vus consécutivement (DDP = 61 ; DT = 272) entre mars 2004 et juillet 2016 ont été inclus dans cette étude. Chacun d'entre eux a été soumis à une évaluation neuropsychologique. On a aussi évalué leur état de santé général, leur humeur, leurs capacités fonctionnelles, leur comportement ainsi que d'autres facteurs sociaux. Ces deux groupes de patients ont ensuite été comparés au moyen des tests du $\chi^{2}$ et de Student. Résultats : Les patients atteints de DDP se sont avérés plus susceptibles d'être mariés, d'occuper un emploi, d'être fumeurs et d'avoir un niveau élevé d'éducation. Ils ont aussi moins signalé des symptômes de nature cognitive ; toutefois, ils en ont signalé davantage de nature dépressive. Ces patients étaient aussi moins susceptibles de vivre seuls et de recourir à des soins à domicile. Quant aux aidants naturels, il a été prouvé qu'ils étaient plus susceptibles d'être un (e) conjoint (e) et qu'ils montraient des niveaux de détresse psychologique plus élevés que ceux s'occupant de patients atteints de DT. Enfin, tant les patients atteints de DDP que ceux atteints de DT étaient également susceptibles de posséder un permis de conduire. Conclusion : Nos résultats indiquent donc que les patients atteints de DDP et de DT donnent à voir des caractéristiques différentes. À cet égard, il ressort que les services offerts aux premiers devraient être modifiés afin de mieux répondre à leurs besoins. Il se pourrait ainsi que le recours à des soins à domicile et du soutien fourni par du personnel soignant atténuent les niveaux élevés de détresse psychologique que l'on a observés chez les patients et leurs aidants naturels. Des efforts additionnels en recherche devraient aussi aborder la dépression dont souffrent ces patients, la détresse psychologique de leurs aidants naturels ainsi que les obstacles à l'obtention de services.

Keywords: Dementia, Caregiving, Memory, Ageing, Depression, Homecare, Homemaking services, Young-onset, Early-onset, Telehealth

doi:10.1017/cjn.2020.8

Can J Neurol Sci. 2020; 47: 320-327

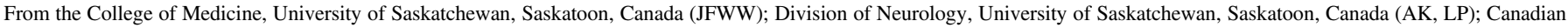

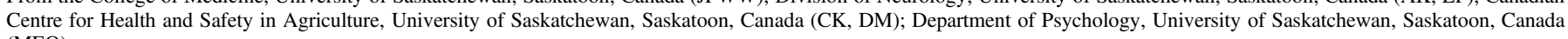
(MEO)

Received September 8, 2019. Final Revisions Submitted January 1, 2020. Date of Acceptance January 4, 2020

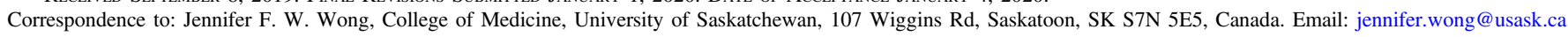




\section{INTRODUCTION}

Young-onset dementia (YOD) is defined as the onset of dementia symptoms before the age of 65 years. ${ }^{1}$ In Canada, YOD accounts for $2-8 \%$ of dementia cases which equates to an estimated 16,000 Canadians under the age of 65 years currently living with dementia. ${ }^{1}$

Although Alzheimer's disease is the most prevalent dementia overall in YOD, Alzheimer's dementia and dementia with Lewy bodies are proportionally more common in late-onset dementia (LOD), while frontotemporal dementia tends to be more common in YOD. ${ }^{2}$ Secondary dementias such as those caused by infection, chronic alcohol abuse, HIV, multiple sclerosis and neoplasms are more common in YOD patients, and some are treatable if interventions are started early. ${ }^{2}$

There is significant financial and social burden in families affected by YOD. Patients diagnosed with YOD face unique challenges. The diagnosis of YOD is often unexpected, resulting in a strain on relationships, the questioning of self-identity, social exclusion and feelings of powerlessness. ${ }^{3}$ Friends and family are less likely to understand the diagnosis of YOD compared to LOD, which can result in social isolation. ${ }^{3}$ Although all dementia patients are more likely to experience apathy ${ }^{4}$ and depression, these feelings are more common among YOD patients. ${ }^{5}$ YOD may also cause financial impacts, early retirement and a high degree of burden on their caregivers and children. ${ }^{2,6,7}$ In YOD, symptoms are often noticed first in the workplace and when these symptoms interfere with work, YOD patients often experience job loss, which can lead to loss of self-identity, autonomy and purpose. $^{8}$ As a consequence of job loss, YOD patients have unmet needs in daytime activities and social company. ${ }^{3,9}$ Patients with YOD often stop driving, ${ }^{10}$ which further results in the loss of freedom and independence.

Spouses of YOD patients encounter higher levels of burden and feelings of depression as caregivers because of increased loneliness, lack of intimacy, assumed responsibility of children, changes in their marital relationship and family conflict. $6,11,12$ Some spouses may feel socially isolated and excluded, especially since YOD is relatively uncommon. ${ }^{13}$ Thus, spouses have a greater need to interact with other people. ${ }^{14}$ Caregivers often experience grief, loss and denial, and many find it difficult to plan for the future. ${ }^{15}$ Spouses often work fewer hours to care for the patient, which can result in financial difficulties and the lack of a meaningful occupation. ${ }^{11}$ As the severity of dementia increases, the spouse often assumes greater responsibility for any dependent children living at home, ${ }^{7}$ and many find it difficult to juggle these additional responsibilities. ${ }^{15}$ Children of YOD patients may gradually take the role of a caregiver instead of themselves receiving parental care. ${ }^{16}$

The province of Saskatchewan in Western Canada has 1.1 million residents and $35.6 \%$ of its population resides in rural regions. ${ }^{17}$ Currently, an estimated 19,000 Saskatchewan residents are living with dementia. ${ }^{18}$ With the large number of rural residents and the growing number of dementia patients, the Rural and Remote Memory Clinic (RRMC) was created in 2004 to increase the accessibility and availability of specialist diagnosis to patients with complex and atypical dementias in rural Saskatchewan. ${ }^{19}$ The RRMC is a one-stop clinic and consists of an interdisciplinary team including a neurologist, neuropsychology team, physical therapist, dietician, and nurse for the streamlined assessment and management of suspected dementia cases. $^{19,20}$ Each new patient receives a standard diagnostic examination that consists of bloodwork, a non-contrast CT scan, multiple neuropsychological tests and additional investigations as indicated. ${ }^{20}$ Using this approach, the time to diagnosis is shortened, with the goal of a diagnosis, treatment recommendation and counselling by the end of the 1-day visit. Each patient with a diagnosis will have a follow-up session with the memory clinic at 6 weeks, 12 weeks and then every 6 months thereafter, and more often as required. ${ }^{19}$ Through the use of telehealth videoconferencing, the time and cost of long-distance travel for patients and caregivers to and from the Memory Clinic for follow-up visits are reduced, ${ }^{19}$ and telehealth has been used for a spousal support group for persons with YOD. ${ }^{13}$ More information on the RRMC can be found in earlier publications. ${ }^{13,19-23}$

Due to the unique challenges that younger patients with dementia face, we aimed to study the differences between young patients ( $<65$ years) and older patients ( $\geq 65$ years) referred to the RRMC in Saskatchewan. The findings from our study will provide information on how to better understand this younger subset of rural dementia patients for improved care and management.

\section{MethodS}

Informed consent was obtained from patients and their caregivers before participation and approved by the University of Saskatchewan Behavioural Ethics Research Board.

\section{Participants}

A total of 544 consecutive patients were seen at the RRMC between March 2004 and July 2016. All patients and their caregivers were given a questionnaire on clinic day. Patients who did not complete all assessments $(n=36)$, did not fill out questionnaires/forms $(n=61)$, who were diagnosed as normal/ "worried well" $(n=105)$, or who did not receive a diagnosis on clinic day $(n=9)$ were excluded from this study. The total number of patients eligible for this study was 333. Patients who were less than 65 years old at the time of diagnosis were considered YOD patients $(n=61)$ and patients who were 65 years or older at the time of diagnosis were considered LOD patients $(n=272)$. As the age of onset of dementia symptoms can be difficult to estimate, we used age at diagnosis to determine the two groups.

\section{Data}

At the clinic, each patient was given a standard battery, which encompassed areas in learning and memory, attention and executive function, visuoperceptual and constructional skills, premorbid intellectual ability, and language. ${ }^{19}$ A list of detailed components can be found in earlier publications. ${ }^{19}$ The MiniMental State Examination (MMSE) was obtained on clinic day as part of a more comprehensive neuropsychological assessment (data not reported here due to known differences in neuropsychological profiles based on different dementia aetiologies, some of which are more likely to be YOD) and additional data were obtained by self-report through questionnaires. The questionnaire given to patients included measures of mood, functional ability, symptoms, memory, health, employment, education, behaviours 
and quality of life. Caregivers were given a questionnaire on measures of caregiver burden, health, and distress and measures of the patient's functional abilities and behaviours.

A number of validated scales were used in the questionnaires to evaluate the severity and burden of symptoms on the patient and their caregiver. These scales were used based on previous literature and included: Mini-Mental State Examination, ${ }^{24,25}$ Depressed Mood Scale, ${ }^{26}$ Functional Assessment Questionnaire, ${ }^{27}$ Brief Symptom Inventory, ${ }^{28}$ Quality of Life Questionnaire, ${ }^{29}$ Bristol Activities of Daily Living Scale, ${ }^{30}$ Self-Rating of Memory Scale, ${ }^{31}$ Zarit Burden Scale, ${ }^{32,33}$ Neuropsychiatric InventorySeverity Scale ${ }^{34}$ and Short-Form Health Survey. ${ }^{35-37}$

\section{Analysis}

A descriptive analysis for the variables was conducted on the two groups. Measures of central tendency and variability were used for continuous variables, while frequency was used for categorical variables. Independent sample $t$-tests were used to compare continuous variables and $\chi^{2}$ tests were used to compare categorical variables between the groups. Exact $p$-values were used when the $\chi^{2}$ test was invalid due to small expected values. Variables with a $p$-value $\leq 0.05$ were considered significant. The data were analysed using IBM SPSS version $24 .^{38}$

\section{RESUltS}

A total of 333 participants were included in this study. The median age of YOD patients $(<65$ years, $n=61$ ) was 59 years and ranged between 44 and 64 years of age. The median age of LOD patients ( $\geq 65$ years, $n=272$ ) was 77 years and ranged between 65 and 94 years of age. The diagnoses made at initial assessment are reported in Table 1. Frontotemporal dementia was diagnosed more frequently among YOD, while Alzheimer's disease was more common in LOD patients $(p<0.001)$.

The characteristics of YOD and LOD patients are reported in Table 2. YOD patients were more likely to be currently married or in a common-law relationship $(p=0.020)$ and have their spouse attend the clinic as a caregiver $(p=0.006)$. They were also more likely to have a high school diploma $(p<0.0001)$, have completed more years of formal school $(p<0.0001)$ and be currently working $(p<0.0001)$. YOD patients were more likely to have their primary source of income from work $(p<0.0001)$, while LOD were more likely to receive their primary source of income from a Canadian pension plan $(p<0.0001)$. LOD patients were more likely to use homecare services $(p=0.016)$, live alone $(p=0.010)$ and be diagnosed with poor vision $(p=0.011)$. YOD patients were more likely to be current smokers $(p<0.0001)$, while LOD patients were more likely to be ex-smokers $(p<0.0001)$. YOD patients were more likely to have a previous diagnosis of stroke $(p=0.022)$, while other diagnoses such as a head injury, poor hearing, heart problems and a psychiatric/ psychological problem or depression did not significantly differ between the two groups. Both were equally as likely to have a driver's licence, and there was no significant difference in metropolitan influenced zone (MIZ), which categorises geographical areas according to the percentage of residents in the area who travel to an urban area for work. However, most of the participants resided in either a CA/CMA or an area with weak
MIZ. There was no difference in having a family history of dementia.

YOD patients had significantly higher scores on the MMSE $(p<0.0001)$ and the Centre for Epidemiologic Studies - Depressed Mood Scale $(p<0.0001)$ indicating less cognitive impairment and more depressive symptoms. Caregivers of YOD scored higher on the Brief Symptom Inventory $(p=0.018)$, indicating higher levels of distress. YOD patients had a lower score on the Functional Assessment Questionnaire $(p=0.013)$, indicating less dependency as measured by the caregiver. There was no significant difference between YOD patients and LOD patients in the Bristol Activities of Daily Living Scale, Quality of Life scale (both patient and caregiver rated), Neuropsychiatric Inventory-Severity Scale, Self-Rating of Memory Scale, indicating that functionality, quality of life and symptoms experienced were similar between the two groups. Caregiver measures such as the Short-Form Health Survey and the Zarit Burden Scale were also similar between the two groups, indicating similar health and burden among caregivers.

\section{Discussion}

Although YOD accounts for only 2-8\% of dementia cases in Canada, ${ }^{1}$ it accounted for $18.3 \%$ of cases in our study through the RRMC. This is not surprising as YOD tends to be more complex to diagnose, and the RRMC was created to provide specialist assessment of complex and atypical cases of dementia. Furthermore, the Canadian Consensus Conference on Diagnosis and Treatment of Dementia guidelines recommend that all YOD patients be seen in specialty clinics. ${ }^{40}$ This subset of dementia patients is often working, married and have young children, making a diagnosis challenging and distressing. YOD patients and their caregivers have distinctly different characteristics, circumstances and experiences from other dementia patients.

\section{Health, Education and Employment}

We found that YOD patients had similar health measures to LOD patients. There were no significant differences in any health-related measures, except that LOD patients were more likely to have poor vision. Both groups were equally likely to have been diagnosed with poor hearing. Hearing loss in adults is quite common. Approximately, $40 \%$ of adults aged 40-59 years have some form of hearing loss, while $78 \%$ of adults aged 60-79 years have hearing loss. ${ }^{41}$ It is important that hearing loss is managed appropriately, as it is a modifiable risk factor for dementia. ${ }^{42,43}$ Interestingly, YOD were twice as likely to have been diagnosed with stroke. This was possibly associated with the greater prevalence of vascular dementia and other secondary dementias in YOD patients. YOD patients were three times more likely to be current smokers, while LOD patients were more likely to be past smokers. Some of this difference in smoking can be attributed to age, as smoking is approximately twice as prevalent in younger adults than in those 65 years or older. ${ }^{44}$

YOD patients were significantly more likely to have a high school diploma and on average completed more years of formal education than LOD patients. YOD patients were more likely to be currently working than LOD patients, which is expected as the standard age of retirement is 65 years. ${ }^{45}$ Although YOD patients 
Table 1. Diagnosis of older $(\geq 65$ years) and younger $(<65$ years) patients in the Rural and Remote Memory Clinic $(n=333)$

\begin{tabular}{l|c|c|c|c}
\hline \multirow{2}{*}{ Diagnosis } & $<\mathbf{6 5}$ years $(\boldsymbol{n}=\mathbf{6 1})$ & $\mathbf{6 6 5}$ years $(\boldsymbol{n}=\mathbf{2 7 2})$ & Total $(\boldsymbol{n}=\mathbf{3 3 3})$ & $\boldsymbol{p}$-value \\
\cline { 2 - 5 } & $n(\%)$ & $\boldsymbol{n}(\boldsymbol{\%})$ & $66(19.8)$ & 0.082 \\
\hline Mild cognitive impairment & $17(27.9)$ & $49(18.0)$ & $37(11.1)$ & $<0.0001$ \\
\hline Frontotemporal dementia & $17(27.9)$ & $20(7.4)$ & $170(51.1)$ & $<0.0001$ \\
\hline Alzheimer's disease & $11(18.0)$ & $159(58.5)$ & $18(5.4)$ & 0.091 \\
\hline Vascular dementia & $6(9.8)$ & $12(4.4)$ & $15(4.5)$ & 0.234 \\
\hline Lewy body dementia & $1(1.6)$ & $14(5.1)$ & $27(8.1)$ & 0.036 \\
\hline Dementia due to other aetiologies & $9(14.8)$ & $18(6.6)$ & & \\
\hline
\end{tabular}

Table 2. Characteristics of younger $\left(<65\right.$ years) patients and older $(\geq 65$ years $), n=333^{*}$

\begin{tabular}{|c|c|c|c|}
\hline \multirow{2}{*}{ Variable } & $<65$ years $(n=61)$ & $\geq 65$ years $(n=272)$ & \multirow{2}{*}{$p$-value } \\
\hline & Mean \pm SD & Mean \pm SD & \\
\hline Years of formal education $(n=312)$ & $12.4 \pm 3.0$ & $10.3 \pm 2.8$ & $<0.0001$ \\
\hline Total years smoked $(n=166)$ & $28.0 \pm 15.6$ & $30.4 \pm 17.9$ & 0.485 \\
\hline $\begin{array}{l}\text { Number of times engaged in physical activity or exercise } \\
\text { per week }(n=276)\end{array}$ & $2.6 \pm 3.7$ & $3.4 \pm 3.4$ & 0.152 \\
\hline Drinks of alcohol per week $(n=283)$ & $2.3 \pm 4.4$ & $1.1 \pm 2.6$ & 0.067 \\
\hline MMSE, total score/30 $(n=301)$ & $25.2 \pm 4.5$ & $22.7 \pm 4.3$ & $<0.0001$ \\
\hline Depressed Mood Scale (depression) $(n=282)$ & $16.7 \pm 9.3$ & $12.3 \pm 8.9$ & 0.002 \\
\hline Bristol Activities of Daily Living Scale $(n=49)$ & $5.7 \pm 6.2$ & $3.6 \pm 5.2$ & 0.299 \\
\hline $\begin{array}{l}\text { Bristol Activities of Daily Living Scale - caregiver } \\
\text { rated }(n=318)\end{array}$ & $7.1 \pm 8.2$ & $8.2 \pm 7.6$ & 0.328 \\
\hline Self-Rating of Memory Scale $(n=275)$ & $-12.5 \pm 8.3$ & $-11.0 \pm 7.7$ & 0.242 \\
\hline $\begin{array}{l}\text { Quality of life of the patient as rated by the patient } \\
(n=273)\end{array}$ & $36.9 \pm 15.4$ & $36.1 \pm 5.4$ & 0.542 \\
\hline $\begin{array}{l}\text { Quality of life of the patient as rated by caregiver } \\
(n=321)\end{array}$ & $32.8 \pm 7.1$ & $32.4 \pm 5.8$ & 0.668 \\
\hline $\begin{array}{l}\text { Functional Assessment Questionnaire - caregiver rated } \\
\qquad(n=326)\end{array}$ & $11.2 \pm 8.4$ & $14.0 \pm 7.8$ & 0.013 \\
\hline $\begin{array}{l}\text { Neuropsychiatric Inventory-Severity - caregiver } \\
\text { rated }(n=292)\end{array}$ & $9.4 \pm 6.5$ & $7.9 \pm 5.7$ & 0.111 \\
\hline Zarit Burden 22-item scale - caregiver self-rated $(n=61)$ & $29.5 \pm 15.1$ & $23.1 \pm 16.3$ & 0.221 \\
\hline $\begin{array}{l}\text { Brief Symptom Inventory-Q1-18 - caregiver self-rated } \\
\quad(n=320)\end{array}$ & $0.4 \pm 0.4$ & $0.3 \pm 0.3$ & 0.018 \\
\hline Perceived change index-caregiver rated $(n=60)$ & $26.0 \pm 3.1$ & $25.6 \pm 2.5$ & 0.646 \\
\hline SF12-Physical component-caregiver self-rated $(n=325)$ & $50.0 \pm 10.5$ & $48.5 \pm 10.2$ & 0.322 \\
\hline \multirow[t]{2}{*}{ SF12- Mental component - caregiver self-rated $(n=325)$} & $50.2 \pm 9.8$ & $52.1 \pm 8.5$ & 0.141 \\
\hline & $n(\%)$ & $n(\%)$ & \\
\hline \multicolumn{4}{|l|}{$\operatorname{Sex}(n=333)$} \\
\hline Male & $32(52.5)$ & $107(39.3)$ & \multirow[t]{2}{*}{0.060} \\
\hline Female & $29(47.5)$ & $165(60.7)$ & \\
\hline \multicolumn{4}{|l|}{ Education level $(n=325)$} \\
\hline$<$ high school & $20(32.8)$ & $155(58.7)$ & \multirow[t]{2}{*}{$<0.0001$} \\
\hline$\geq$ high school & $41(67.2)$ & $109(41.3)$ & \\
\hline \multicolumn{4}{|l|}{ Marital status $(n=323)$} \\
\hline Married/common law & $49(80.3)$ & $170(64.9)$ & \multirow[t]{2}{*}{0.020} \\
\hline Other (single, divorced, separated, widowed) & $12(19.7)$ & $92(35.1)$ & \\
\hline
\end{tabular}


Table 2. (Continued)

\begin{tabular}{|c|c|c|c|}
\hline \multirow{2}{*}{ Variable } & $<65$ years $(n=61)$ & $\geq 65$ years $(n=272)$ & \multirow{2}{*}{$p$-value } \\
\hline & Mean \pm SD & Mean \pm SD & \\
\hline \multicolumn{4}{|l|}{ Hours currently working $(n=266)$} \\
\hline None & $34(69.4)$ & $197(90.8)$ & \multirow[t]{2}{*}{$<0.0001$} \\
\hline Some & $15(30.6)$ & $20(9.2)$ & \\
\hline \multicolumn{4}{|l|}{ Lived with $(n=323)$} \\
\hline Alone & $5(8.2)$ & $64(24.4)$ & \multirow[t]{3}{*}{0.010} \\
\hline Spouse or partner only & $39(63.9)$ & $153(58.4)$ & \\
\hline Other (family members/friends, roommates, boarders) & $17(27.9)$ & $45(17.2)$ & \\
\hline \multicolumn{4}{|l|}{ Smoking status $(n=321)$} \\
\hline Current smoker & $20(32.8)$ & $27(10.4)$ & \multirow[t]{3}{*}{$<0.0001$} \\
\hline Ex-smoker & $16(26.2)$ & $114(43.8)$ & \\
\hline Never smoker & $25(41.0)$ & $119(45.8)$ & \\
\hline \multicolumn{4}{|l|}{ Primary source of income $(n=319)$} \\
\hline Employment & $15(25.9)$ & $5(1.9)$ & \multirow[t]{3}{*}{$<0.0001^{\#}$} \\
\hline Canada Pension Plan & $8(13.8)$ & $160(61.3)$ & \\
\hline $\begin{array}{l}\text { Other (social assistance, EI, disability, workers } \\
\text { compensation, family and other) }\end{array}$ & $35(60.3)$ & $96(36.8)$ & \\
\hline
\end{tabular}

Valid driver's licence $(n=322)$

\begin{tabular}{|c|c|c|c|}
\hline No & $12(20.0)$ & $73(27.9)$ & \multirow[t]{2}{*}{0.213} \\
\hline Yes & $48(80.0)$ & $189(72.1)$ & \\
\hline \multicolumn{4}{|c|}{ Services used- homecare, homemaking services $(n=163)$} \\
\hline No & $20(95.2)$ & $100(70.4)$ & \multirow[t]{2}{*}{0.016} \\
\hline Yes & $1(4.8)$ & $42(29.6)$ & \\
\hline \multicolumn{4}{|c|}{ Family history of dementia $(n=327)$} \\
\hline No & $29(49.2)$ & $112(41.8)$ & \multirow[t]{2}{*}{0.301} \\
\hline Yes & $30(50.8)$ & $156(58.2)$ & \\
\hline \multicolumn{4}{|c|}{ Diagnosed with heart disease/any other heart problems $(n=253)$} \\
\hline No & $29(70.7)$ & $132(62.3)$ & \multirow[t]{2}{*}{0.302} \\
\hline Yes & $12(29.3)$ & $80(37.7)$ & \\
\hline \multicolumn{4}{|c|}{ Diagnosed with poor hearing $(n=273)$} \\
\hline No & $30(63.8)$ & $119(52.7)$ & \multirow[t]{2}{*}{0.162} \\
\hline Yes & $17(36.2)$ & $107(47.3)$ & \\
\hline \multicolumn{4}{|c|}{ Diagnosed with poor vision $(n=284)$} \\
\hline No & $35(72.9)$ & $125(53.0)$ & \multirow[t]{2}{*}{0.011} \\
\hline Yes & $13(27.1)$ & $111(47.0)$ & \\
\hline \multicolumn{4}{|c|}{ Diagnosed with stroke $(n=234)$} \\
\hline No & $27(69.2)$ & $165(84.6)$ & \multirow[t]{2}{*}{0.022} \\
\hline Yes & $12(30.8)$ & $30(15.4)$ & \\
\hline \multicolumn{4}{|c|}{ Diagnosed with head injury $(n=254)$} \\
\hline No & $29(65.9)$ & $162(77.1)$ & \multirow[t]{2}{*}{0.117} \\
\hline Yes & $15(34.1)$ & $48(22.9)$ & \\
\hline \multicolumn{4}{|c|}{ Diagnosed with psychiatric/psychological problem and depression $(n=239)$} \\
\hline No & $26(66.7)$ & $149(74.5)$ & \multirow[t]{2}{*}{0.312} \\
\hline Yes & $13(33.3)$ & $51(25.5)$ & \\
\hline
\end{tabular}


Table 2. (Continued)

\begin{tabular}{|c|c|c|c|}
\hline \multirow{2}{*}{ Variable } & $<65$ years $(n=61)$ & $\geq 65$ years $(n=272)$ & \multirow{2}{*}{$p$-value } \\
\hline & Mean \pm SD & Mean \pm SD & \\
\hline \multicolumn{4}{|c|}{ Metropolitan influenced zone $e^{\dagger}(n=331)$} \\
\hline No MIZ & $3(5.0)$ & $32(11.8)$ & \multirow[t]{5}{*}{0.104} \\
\hline Weak MIZ & $20(33.3)$ & $96(35.4)$ & \\
\hline Moderate MIZ & $8(13.3)$ & $46(17.0)$ & \\
\hline Strong MIZ & $0(0.0)$ & $8(3.0)$ & \\
\hline $\mathrm{CA} / \mathrm{CMA}$ & $29(48.3)$ & $89(32.8)$ & \\
\hline \multicolumn{4}{|c|}{ Respondent completing the questionnaire - relationship to patient $(n=310)$} \\
\hline Wife & $23(42.6)$ & $76(29.7)$ & \multirow[t]{5}{*}{0.006} \\
\hline Husband & $15(27.8)$ & $44(17.2)$ & \\
\hline Son & $2(3.7)$ & $29(11.3)$ & \\
\hline Daughter & $6(11.1)$ & $79(30.9)$ & \\
\hline Other & $8(14.8)$ & $28(10.9)$ & \\
\hline
\end{tabular}

Weak MIZ: $<5 \%$ of the workforce commutes to a CA/CMA. Moderate MIZ: 5-29\% of the workforce commutes to a CA/CMA. Strong MIZ: $>30 \%$ of the workforce commutes to a CA/CMA. CA: population $\geq 10,000$. CMA: population $\geq 100,000 .{ }^{39}$ EI: employment insurance.

Bold values indicate significance $(p \leq 0.05)$.

*All variables have missing values except age and sex.

\#Due to small expected values, exact test $p$-value was reported.

$\dagger$ No MIZ: none of the workforce commutes to a CA/CMA.

were more likely to be currently working, only one-third were working at the time of diagnosis and about a quarter had employment as a major source of income. This lack of employment in YOD patients may stem from dementia symptoms interfering with work. ${ }^{8}$ In addition to loss of occupation, patients with YOD often cease driving after diagnosis. ${ }^{10}$ Approximately, $80 \%$ of YOD patients had a driver's licence, which is similar to LOD patients, despite LOD patients being almost twice as likely to have a diagnosis of poor vision. Although there was no difference in MIZ scores between YOD and LOD patients, the majority of participants in both groups resided in either larger centres (population $\geq 10,000$ ) or rural areas with a weak MIZ where a small fraction of workers commute to larger centre. People who benefit from this service may be more likely to live in towns that may not offer such services or more remote areas that are less influenced by larger cities. This suggests a need of more accessible services in smaller and rural areas.

\section{Cognition, Depression and Quality of Life}

We found that YOD patients had significantly less cognitive impairment as measured by a screening test, which may be a factor in the higher proportion of YOD patients who could work. Although YOD patients in the current study were less cognitively impaired, there was no difference in severity of caregiver-reported dementia symptoms between YOD and LOD patients as measured by the Neuropsychiatric Inventory-Severity scale.

YOD patients in this study had higher levels of depression than LOD patients. Depression may be more prevalent in YOD patients due to the unexpected nature of YOD, which can cause a questioning of self-identity, and strain on relationships, especially when children are involved., ${ }^{2,3}$ Depression is associated with lower quality of life. ${ }^{46}$ We found that although YOD patients were more likely to experience depressive symptoms, the quality of life of patients was not significantly different between YOD patients and LOD patients.

\section{Caregiver Distress and Burden}

YOD patients were more likely to be currently married or in a common-law relationship and to have their spouse attend the clinic as a caregiver, due to death of spouses in the LOD group. Caregivers of YOD patients in our study scored significantly higher on the Brief Symptom Inventory scale indicating a higher level of caregiver general psychological distress. Despite increased caregiver psychological distress, caregiver burden did not differ between the two groups. Other studies have found that caregiver burden is higher in YOD patients. ${ }^{11,47}$ Spouses of YOD patients tend to experience a high level of distress, stress, caregiver burden, depression and coping difficulties. ${ }^{6,11,15,47}$ Increased caregiver psychological distress can be due to a variety of reasons. Spouses of YOD patients often assume additional responsibilities such as caring for children and the patient, becoming the breadwinner, and making important financial and social decisions. ${ }^{6,711}$ YOD caregivers are more likely to experience greater levels of psychological suffering, especially with patient behavioural symptoms ${ }^{11}$ and may benefit from caregiver support groups. ${ }^{48}$

Our study found that YOD patients were more likely to live with their spouse. Living in the same home as a patient with dementia can cause caregivers to assume additional responsibilities they may not have undertaken if the patient lived alone and may cause distress for the caregiver as they watch their loved one deteriorate. Living with a caregiver may also decrease the perceived need to use homecare services. It has been found that 
the use of these services is associated with reduced depression in caregivers. ${ }^{49}$ In our study, YOD patients were six times less likely to access homecare services or homemaking services than LOD patients. YOD patients are less likely to access services for a variety of reasons, including barriers such as unaffordability, ineligibility, insecurity, lack of childcare and a lack of perceived need. ${ }^{50}$ Available services are frequently tailored for LOD patients and thus the lack of fit for YOD patients also proves a barrier, ${ }^{51}$ and YOD patients and their caregivers may choose not to access care because of denial and refusal to seek help. ${ }^{52}$ Accessing services for YOD may be especially important for YOD patients, as this population has a high mortality from complications due to dementia. ${ }^{53}$

\section{Limitations}

Although the definition of YOD is the onset of dementia symptoms before the age of 65 years, we were only able to measure YOD as a diagnosis of dementia before the age of 65 years because age of onset is always a retrospective estimate prone to inaccuracy. Compared to national estimates, a much larger proportion of patients referred to the RRMC were YOD patients. The RRMC also serves rural patients who may differ from urban patients. Finally, having multiple comparisons in our data makes spurious findings more likely.

\section{Conclusion}

YOD patients are distinctly different from LOD patients. YOD patients are more educated, more likely to be working and are more likely to be married. Because of this, YOD patients experience unique challenges in receiving a diagnosis and are more likely to demonstrate depressive symptoms. Caregivers of YOD patients demonstrate higher levels of general psychological distress. Homecare services should be modified to better assist YOD patients and additional support is needed for their caregivers. More research is needed to better understand how to help YOD patients overcome barriers to services and how we can shape these services to better fit the needs of YOD patients and their families.

\section{ACKNOWLEDGements}

We would like to acknowledge the Rural and Remote Memory Clinic at the University of Saskatchewan for support in this research.

\section{Funding}

This study was funded by the College of Medicine, University of Saskatchewan.

\section{Disclosures}

The authors have no conflicts of interest to declare.

\section{Statement OF AUTHORShIP}

All authors contributed in the preparation and editing of the final manuscript. JFWW wrote the manuscript under the guidance of AK. AK and LP developed the study design and oversaw data collection. CK conducted the statistical analysis. DM managed data collection. MEOC administered and oversaw neuropsychological testing.

\section{REFERENCES}

1. Alzheimer Society of Canada. Prevalence and monetary costs of dementia in Canada. Toronto $(\mathrm{ON})$ : Alzheimer Society of Canada; 2016.

2. Draper B, Withall A. Clinical perspectives: young onset dementia. Intern Med J. 2016;46(7):779-86.

3. Greenwood N, Smith R. The experiences of people with youngonset dementia: a meta-ethnographic review of the qualitative literature. Maturitas. 2016;92:102-9.

4. Appelhof B, Bakker C, Van Duinen-van Den IJssela JCL, et al. Differences in neuropsychiatric symptoms between nursing home residents with young-onset dementia and late-onset dementia. Aging Ment Health. 2019;23(5):581-6.

5. Leontjevas R, van Hooren S, Waterink W, Mulders A. Apathy and depressive mood in nursing home patients with early-onset dementia. Am J Alzheimers Dis Other Demen. 2009;24(4): $341-8$.

6. Millenaar JK, de Vugt ME, Bakker C, et al. The impact of young onset dementia on informal caregivers compared with late onset dementia: results from the NeedYD study. Am J Geriatr Psychiatry. 2016;24(16):467-74.

7. Gelman C, Rhames K. "I have to be both mother and father": the impact of young-onset dementia on the partner's parenting and the children's experience. Dementia. 2018:1-15. doi: 10.1177/ 1471301218783542.

8. Roach P, Drummond N. 'It's nice to have something to do': earlyonset dementia and maintaining purposeful activity. J Psychiatr Ment Health Nurs. 2014;21(10):889-95.

9. Bakker C, de Vugt ME, van Vliet D, et al. Predictors of the time to institutionalization in young- versus late-onset dementia: results from the needs in Young Onset Dementia (NeedYD) study. J Am Med Dir Assoc. 2013;14(4):248-53.

10. Velayudhan L, Baillon S, Urbaskova G, et al. Driving cessation in patients attending a young-onset dementia clinic: a retrospective cohort study. Dement Geriatr Cogn Discord Extra. 2018;8:190-8.

11. van Vliet D, de Vugt ME, Bakker C, Koopmans RT, Verhey FR. Impact of early onset dementia on caregivers: a review. Int J Geriatr Psychiatry. 2010;25(11):1091-100.

12. Holdsworth K, McCabe M. The impact of younger-onset dementia on relationships, intimacy, and sexuality in midlife couples: a systematic review. Int Psychogeriatr. 2018;30(1):15-29.

13. O'Connell ME, Crossley AC, Morgan D, et al. Development and evaluation of a telehealth video conferenced support group for rural spouses of individuals diagnosed with atypical early-onset dementias. Dementia. 2014;13(3):382-95.

14. Wawrziczny E, Pasquier F, Ducharme F, Kergoat M, Antoine P. Do spouse caregivers of young and older persons with dementia have different needs? A comparative study. Psychogeriatrics. 2017; 17:282-91.

15. Durcharme F, Kergoat M, Antoine P, Pasquier F, Coulombe R. The unique experience of spouses in early-onset dementia. Am J Alzheimers Dis Other Demen. 2013;28(6):634-41.

16. Millenaar JK, van Vliet $\mathrm{D}$, Bakker $\mathrm{C}$, et al. The experiences and needs of children living with a parent with young onset dementia: results from the NeedYD study. Int Psychogeriatr. 2014;26(12): 2001-10.

17. Statistics Canada. Focus on Geography Series, 2016 Census; 2017. Retrieved from: https://www12.statcan.gc.ca/census-recensement/ 2016/as-sa/fogs-spg/Facts-pr-eng.cfm?Lang=Eng\&GK=PR\&GC $=$ 47\&TOPIC $=1$; accessed October 18, 2018.

18. Alzheimer Society of Canada. Dementia in Saskatchewan; 2017. Retrieved from: http://alzheimer.ca/en/sk/Vote-Dementia-Care/ Dementia-SK; accessed August 14, 2018.

19. Morgan DG, Crossley M, Kirk A, et al. Improving access to dementia care: development and evaluation of a rural and remote memory clinic. Aging Ment Health. 2009;13(1):17-30.

20. Verity R, Kirk A, O'Connell M, Karunanayake C, Morgan D. The Worried Well? Characteristics of cognitively normal patients 
presenting to a rural and remote memory clinic. Can J Neurol Sci. 2018;45(2):158-67.

21. Lacny C, Kirk A, Morgan DG, Karunanayake C. Does day length affect cognitive performance in memory clinic patients? Can J Neurol Sci. 2011;38:461-4.

22. Lacny C, Kirk A, Morgan DG, Karunanayake C. Predictors of cognitive impairment severity in rural patients at a memory clinic. Can J Neurol Sci. 2012;39:774-81.

23. Hager D, Kirk A, Morgan DG, Karunanayake C, O'Connell M. Predictors of cognitive decline in a rural and remote Saskatchewan population with Alzheimer's disease. Am J Alzheimers Dis Other Demen. 2016;31(8):643-9.

24. Folstein MF, Folstein SE, McHugh PR. Mini-Mental State: a practical method for grading the cognitive state of patients for the clinician. J Psychiatr Res. 1975;3:189-98.

25. McEachern W, Kirk A, Morgan DG, Crossley M, Henry C. Reliability of the MMSE administered in-person and by telehealth. Can J Neurol Sci. 2008;35:643-6.

26. Radloff LS. The CES-D Scale: a self-report depression scale for research in the general population. Appl Psych Meas. 1977;1: 385-401.

27. Pfeffer R, Kurosaki T, Harrah C, Chance J, Filos S. Measurement of functional activities in older adults in the community. J Gerontol. 1982;37:323-29.

28. Derogatis LR, Melisaratos N. The brief symptom inventory: an introductory report. Psychol Med. 1983;13:595-605.

29. Logsdon RG, Gibbons LE, McCurry SM, Teri L. Quality of life in Alzheimer's disease: patient and caregiver reports. J Ment Health Aging. 1999;5(1):21-32.

30. Bucks RS, Ashworth DL, Wilcock GK, Siegfried K. Assessment of activities of daily living in dementia: development of the Bristol Activities of Daily Living Scale. Age Ageing. 1996;25:113-20.

31. Squire LR, Zouzounis JA. Self-ratings of memory dysfunction: different findings in depression and amnesia. JCEN. 1988;10(6): 727-38.

32. Zarit SH, Orr NK, Zarit JM. The hidden victims of Alzheimer's disease: families under stress. New York: New York University Press; 1985.

33. O'Rourke N, Tuokko HA. Psychometric properties of an abridged version of the Zarit Burden interview within a representative Canadian caregiver sample. Gerontologist. 2003;43(1):121-7.

34. Cummings JL. The Neuropsychiatric Inventory: assessing psychopathology in dementia patients. Neurology. 1997;48:S10-6.

35. Ware JE, Kosinski M, Turner-Bowker DM, Gandek B. How to score version 2 of the SF-12 health survey. Lincoln, RI: QualityMetric Incorporated; 2002.

36. Ware JE, Kosinski M, Keller SD. SF-36 physical \& mental component summary measures-a user's manual. Boston, MA: The Health Assessment Lab, New England Medical Center; 1994.

37. Quality metric health outcomes scoring software 4.5-user's guide. Lincoln, RI: Quality Metric Incorporated; 2002.
38. IBM Corporation. IBM SPSS statistics for Windows, version 22.0. Armonk, NY: IBM Corporation; 2013.

39. Statistics Canada. Census metropolitan influenced zones: detailed definition; 2018. Retrieved from: https://www150.statcan. gc.ca/n1/pub/92-195-x/2011001/other-autre/miz-zim/def-eng.htm; accessed November 24, 2019.

40. Moore A, Patterson C, Lee L, Vedel I, Bergman H. Fourth Canadian Consensus Conference on the diagnosis and treatment of dementia. Can Fam Physician. 2014;60(5):433-8.

41. Statistics Canada. Hearing loss of Canadians, 2012 to 2015; 2016. Retrieved from: -https://www150.statcan.gc.ca/n1/pub/82-625x/2016001/article/14658-eng.htm; accessed November 24, 2019.

42. Livingston G, Sommerlad A, Orgeta V, et al. Dementia, intervention, and care. The Lancet. 2017;390(10113):2673-734.

43. Kim SY, Lim JS, Kong IG, Choi HG. Hearing impairment and the risk of neurodegenerative dementia: a longitudinal follow-up study using a national sample cohort. Sci Rep. 2018;8:15266.

44. Statistics Canada. Smokers, by age group; 2018. Retrieved from: https://www150.statcan.gc.ca/t1/tbl1/en/tv.action?pid= 1310009610; accessed June 15, 2018

45. Government of Canada. Canada Pension Plan - how much could you receive; 2018 https://www.canada.ca/en/services/benefits/ publicpensions/cpp/cpp-benefit/amount.html; accessed June 29, 2018.

46. Sivertsen H, Bjorklof GH, Engedel K, Selbaek G, Helvik AS. Depression and quality of life in older patients: a review. Dement Geriatr Cogn Disord. 2015;40:311-39.

47. Lim L, Zhang A, Lim L, et al. High caregiver burden in young onset dementia: what factors need attention? J Alzheimer's Dis. 2018; 61(2):537-43.

48. Goy E, Kansagara D, Freeman M. A systematic evidence review of interventions for non-professional caregivers of individuals with dementia. Washington, DC: Department of Veterans Affairs; 2010.

49. Rosness TA, Mjorud M, Engedal K. Quality of life and depression in carers of patients with early onset dementia. Aging Ment Health. 2011;15(3):299-306.

50. Cations M, Withall A, Horsfall R, et al. Why aren't people with young onset dementia and their supporters using formal services? Results from the INSPIRED study. PLoS ONE. 2017;12(7): $\mathrm{e} 0180935$

51. Bakker C, de Vugt ME, Vernooij-Dassen M, van Vliet D, Verhey FR, Koopmans RT. Needs in early onset dementia: a qualitative case from the NeedYD study. Am J Alzheimers Dis Other Demen. 2010;25(8):634-40.

52. van Vliet D, de Vugt ME, Bakker C, et al. Caregivers' perspectives on the pre-diagnostic period in early onset dementia: a long and winding road. Int Psychogeriatr. 2011:23(9);1393-404.

53. Tan B, Fox S, Kruger C, Lynch M, Shanagher D, Timmons S. Investigating the health utilization and support needs of people with young-onset dementia. Maturitas. 2019;122:31-4. 